\title{
QbD Based Optimization of Curcumin Nanoemulsion: DoE and Cytotoxicity Studies
}

\author{
Shambhavi Dhananjay Acharya ${ }^{1}$, Preeti Kaustubh Tamane $^{2}$, Shyam Nagarao Khante', \\ Varsha Babu Pokharkar ${ }^{3, *}$
}

1'Department of Quality Assurance Techniques, Bharati Vidyapeeth (Deemed to be University), Poona College of Pharmacy, Erandwane, Maharashtra, INDIA.

${ }^{2}$ Department of Drug Regulatory Affairs, Bharati Vidyapeeth (Deemed to be University), Poona College of Pharmacy, Erandwane, Pune, Maharashtra, INDIA.

${ }^{3}$ Department of Pharmaceutics, Bharati Vidyapeeth (Deemed to be University), Poona College of Pharmacy, Erandwane, Pune, Maharashtra, INDIA.

\begin{abstract}
Aim: The aim of this study was to employ a Quality by design ( $Q b D)$ based approach for the development and optimization of stable curcumin (CUR) nanoemulsion (NE). Materials and Methods: The NE was developed using Tween 80 as surfactant, Tocopheryl polyethylene glycol 1000 succinate (TPGS) as cosurfactant and Kollisolv MCT 70 as oil phase. The Design of Experiment (DoE) consisted of a 3 level- 2 factor full factorial design for the optimization. The independent variables were concentration of surfactant mix (Smix) and oil phase while particle size, zeta potential and polydispersity index (PDI) were the dependent variables. The NE was evaluated for particle size, zeta potential, $\mathrm{pH}$, viscosity, transmittance, drug content, in-vitro drug release, stability and in vitro anticancer activity. Results: The optimized formulation showed approximate particle size of $17 \mathrm{~nm}$, zeta potential -12.8 and polydispersity index 0.161 and was stable for three months at room temperature. The nanoemulsion showed better activity as compared to pure drug against pituitary and colon cancer cell-lines. Conclusion: QbD based approach can aid in the development of robust and thermodynamically stable NEs.
\end{abstract}

Key words: Nanoemulsion, QbD, Curcumin, Full factorial design, DoE.

\section{INTRODUCTION}

Curcumin (CUR) is a polyphenol obtained from rhizomes of turmeric, Curcuma longa Linn. (Zingiberaceae). CUR exhibits a number of pharmacological activities including antioxidant, anti-inflammatory, antimicrobial, as well as anticancer. The use of CUR is greatly limited due to its low aqueous solubility, low permeability and hence low bioavailability. CUR is a BCS (Biopharmaceutical Classification System) Class IV drug. Number of dosage forms have been developed to in order to overcome this limitation of CUR so as exploit its therapeutic potential. ${ }^{1}$ A nanoemulsion (NE) is a biphasic system which consists of an oil phase and an aqueous phase which are held together by surfactants and/or co surfactants. NEs are basically of two type's oil-in-water $(\mathrm{o} / \mathrm{w})$ where the oil phase is dispersed in the water phase and water-inoil (w/o) where the water is the dispersed phase. The oil selected must be non-toxic in nature. Surfactants are used to stabilize the system and could be non-ionic, zwitterionic, anionic or cationic in nature. ${ }^{2}$ Nanoformulations are defined as formulations having particle size in the range of 10-100 $\mathrm{nm}$. Such small particle size of the dispersed phase is stabilized by the interfacial film of the surfactant which reduces the interfacial tension. Due to small particle size nanoemulsions are transparent in nature. ${ }^{3}$ NEs are considered to be kinetically stable while thermodynamically unstable. ${ }^{4}$ An o/w NE can aid in solubilizing lipophilic drugs. Also, it increases bioavailability and rate of
Submission Date: 21-08-2019; Revision Date: 05-11-2019; Accepted Date: 23-01-2019

DOI: 10.5530/ijper.54.2.38 Correspondence:

Dr. Varsha Babu Pokharkar, Department of Pharmaceutics, Bharati Vidyapeeth (Deemed to be University), Poona College of Pharmacy, Erandwane, Pune-411038, Maharashtra, INDIA.

Phone: +919422032985

E-mail: varsha.pokharkar@ bharatividyapeeth.edu

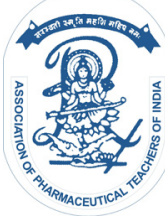

www.ijper.org 
absorption. NE can carry both lipophilic and hydrophilic drugs at the same time. NEs can be used in case of parenteral, oral, topical, ocular and transdermal drug delivery system and in cosmetics. NEs have also been used for targeted drug delivery. ${ }^{5}$

Various nanoformulations of CUR have been reported previously. NEs have been developed to overcome the limitations associated with use of CUR including poor solubility and bioavailability. ${ }^{6}$ CUR loaded NE has been tested for effectiveness against various types of cancer including metastatic ones. ${ }^{7-9}$ Percentage of oil and cosurfactant have shown to have effect on particle size. ${ }^{10,11}$ However, the stability of developed NEs has been reported in only few studies. ${ }^{12}$

Quality must be built into the product. For this, an understanding of material attributes, process parameters and formulation parameters that influence product quality is required..$^{13}$ Quality by Design (QbD) is a systematic approach to pharmaceutical development that begins with predefined objectives and emphasizes product and process understanding and process control, based on science and quality risk management. ${ }^{14}$ QbD streamlines troubleshooting and aids in the development of robust formulations. ${ }^{15} \mathrm{QbD}$ has been successfully used for development of number of NEs. ${ }^{16}$

The aim of the present study was to develop and optimize an oil o/w NE for CUR in order to overcome poor solubility of the drug. As NEs are thermodynamically unstable; a QbD based optimization design was applied in order to obtain a stable and robust NE with improved stability as well as efficacy. Since curcumin is reported to have excellent anti-cancer activity, the main focus was to evaluate the nanoemulsion in cancer cell lines, especially pituitary cancer wherein there are no reports yet of curcumin being tried for this type of cancer. The NE has shown promising results in vitro and further in vivo pharmacokinetic studies will be useful in determining the appropriate route for its administration.

CUR NE was optimized using $3^{2}$ full factorial design with 3 levels of 2 independent factors (concentration of Smix and oil). While dependent variables selected were particle size, zeta potential and polydispersity index (PDI). QbD was primarily employed during optimization with the objective of developing a stable formulation. Particle Size zeta potential and PDI are indicators of the stability of a nanoformulation and hence they were chosen as dependent variables.

\section{MATERIALS AND METHODS}

\section{Chemicals}

CUR was received as gift sample from OmniActive Health Technologies, Pune. Kollisolve MCT 70, Pro- pylene Glycol (PG) were received as gift sample from Signet Chemical Corporation Pvt. Ltd, Mumbai and Tocopheryl polyethylene glycol 1000 succinate (TPGS) was gift sample from Antares Health Products, INC. Miglyol 812 was received as gift sample from IOI Oleochemicals, Germany. Tween 80 was purchased from Merck (Mumbai). Methanol used was of analytical grade. Dialysis membrane was from Himedia.

\section{Solubility Studies}

Saturation solubility of CUR in different oils (Miglyo 1812, Kollisolv MCT 70 and Phosal 53) was determined by addition of excess drug in $1 \mathrm{~mL}$ of each oil separately in stoppered vials and mixed using vortex mixer. The vials were then kept in isothermal shaker for $72 \mathrm{hr}$ to reach equilibrium, at $25 \pm 1.0^{\circ} \mathrm{C}$. These samples were then centrifuged at $3000 \mathrm{rpm}$ for $15 \mathrm{~min}$. The supernatant was taken after centrifugation and diluted with methanol as required. The content of CUR in each sample was determined using ultraviolet (UV) spectrophotometer at $417 \mathrm{~nm}$ (Jasco V-630, JASCO Inc., USA). ${ }^{17}$

\section{Screening of Surfactants and Co-surfactants}

$15 \% \mathrm{v} / \mathrm{v}$ solutions of surfactants namely Tween 20, Tween 40 and Tween 80 were prepared. $5 \mu \mathrm{L}$ of oil were added to the $2.5 \mathrm{~mL}$ of above solutions followed by vigorous vortexing. Addition of oil was continued until the surfactant solution became cloudy.

The selected surfactant was mixed with 2 co surfactants namely Tocopheryl polyethylene glycol 1000 succinate and propylene glycol in different volume ratios (Smix). For each of these fixed Smix ratio, pseudo ternary phase diagrams were constructed using water titration method. For this 12 different oil to Smix ratios were selected including 1:9, 1:8, 1:7, 1:6, 1:5, 1:4, 1:3, 1:2, 1:1, 2:1, 6:1 and 9:1. Water was added in the range of 5\%-95\% with $5 \%$ interval by vigorous vortexing. After each addition visual observation was made and recorded, to classify the resultant mixture as NE, Nanogel (Ngel), Emulsion (E) and emulgel (EG).

Visual observations were made and recorded after each water volume addition to know the region of NE. Further, calculation of $\%$ Smix, $\%$ oil and $\%$ aqueous phase was done for each Oil: Smix ratio. Pseudo ternary phase diagrams were plotted to delineate the region for $\mathrm{NE}$ formation.

\section{Thermodynamic Stability Studies}

Three formulations with varying oil content were selected based on the pseudo ternary phase diagrams. To evaluate thermodynamic stability of the selected NEs, the formulations were subjected to centrifugation (at 3,500 rpm for $30 \mathrm{~min}$ at room temperature), heating- 
cooling cycles (three cycles of $24 \mathrm{hr}$ at $4^{\circ} \mathrm{C}$ and $45^{\circ} \mathrm{C}$ each) and freeze-thaw cycles (three cycles of $24 \mathrm{hr}$ each for at $0^{\circ} \mathrm{C}$ and room temperature each). The formulations were visually checked for any instability. ${ }^{18}$

\section{Optimization of CUR NE by Full Factorial Design}

The NE was optimized using a three level two factor design. The design was employed to see the effect of independent variables on dependent variables. In this case 2 independent variables were concentration of Smix and oil while dependent variables were particle size, zeta potential and polydispersity index..$^{19,20}$

\section{Globule Size and Zeta Potential Analysis}

The droplet size, PDI and zeta potential of NE was determined using a nano particle analyzer (Nano Partica, Horiba Scientific SZ-100). Light scattering was monitored at $25^{\circ} \mathrm{C}$ at $90^{\circ}$ angle.

\section{Physicochemical Characterization of optimized NE}

The $\mathrm{pH}$ of the formulations was measured by a $\mathrm{pH}$ meter. Viscosity of NE was determined by Brookfield viscometer (Brookfield Engineering Laboratories, Middleboro, MA). Viscosity was calculated using spindle \#1 at 6 RPM and calculated in centi Poise. Transmittance of the NE was determined by using UV spectrophotometer.

\section{Transmission Electron Microscopy}

Morphology of NE was examined by transmission electron microscopy (TEM; TEM JEM-2010-JEOL, Tokyo, Japan). The NE was dispersed in water and one drop of diluted dispersion placed on a 200-mesh carbon-coated copper grid. The grid was then dried at room temperature and then observed by TEM.

\section{Drug Content}

Absorbance of prepared NE and filtered NE (through $0.45 \mu \mathrm{m}$ syringe filter) was measured after proper dilution using a UV Spectrophotometer.

\section{Stability Studies}

To study the physical stability, drug loaded NE was kept at room temperature and refrigerator $\left(2-8^{\circ} \mathrm{C}\right)$ for 3 months. Formulation was checked visually for any instability and further for globule size, zeta potential and PDI.

\section{In- vitro Release Studies}

In-vitro release studies were performed using dialysis membrane-50 with average flat width and diameter $24.26 \mathrm{~mm}$ and $14.3 \mathrm{~mm}$ respectively. The dialysis membrane was cut appropriately to accommodate $2 \mathrm{~mL}$ of
NE (corresponding to $1 \mathrm{mg}$ of curcumin). Dialysis bags were tied properly from both the sides after addition of $\mathrm{NE}$ and suspended in a beaker containing phosphate buffered saline $(\mathrm{pH}$ 7.2) which was then placed on a magnetic stirrer. Aliquots of $3 \mathrm{~mL}$ were withdrawn every hour up to $8 \mathrm{hr}$. Each aliquot was replaced with $3 \mathrm{~mL}$ of fresh buffer maintained at $37^{\circ} \mathrm{C}$ to maintain sink conditions. The $\%$ release and release kinetics of the drug from the NE was evaluated. ${ }^{19,21}$ In-vitro release kinetics of the drug was performed by dissolving CUR in methanol $(2 \mathrm{~mL}$ solution of concentration $0.5 \mathrm{mg} / \mathrm{ml}$ was used; thus $1 \mathrm{mg}$ drug was used for the study).

\section{In-vitro cell line studies}

This study was performed on the 2 cancer cell lines. The cell lines were cultured in DMEM (Dulbecco's Modified Eagle Medium) which was supplemented with 10\% heat inactivated foetal calf serum (FBS) and 1\% Antibiotic - Antimycotic solution. The cells were seeded at a density of approximately $5 \times 10^{3}$ cells/well in a 96-well flat-bottom micro plate and maintained at $37^{\circ} \mathrm{C}$ in $95 \%$ humidity and 5\% $\mathrm{CO}_{2}$ overnight. Cells were treated with different concentrations $(500,250,125,62.5,31.25 \mu \mathrm{g} /$ $\mathrm{mL}$ ) of samples. The cells were incubated for another $24 \mathrm{hr}$.

The cells in well were washed twice with phosphate buffer and $20 \mu \mathrm{L}$ of the MT'T 3-(4,5-dimethylthiazol-2-yl)2,5-diphenyltetrazolium bromide staining solution (5 $\mathrm{mg} / \mathrm{ml}$ in phosphate buffer solution) was added to each well and plate was incubated at $37^{\circ} \mathrm{C}$. After $4 \mathrm{hr}, 100 \mu \mathrm{L}$ of di- methyl sulfoxide (DMSO) was added to each well to dissolve the formazan crystals and absorbance was recorded with a $570 \mathrm{~nm}$ using micro plate reader.

\section{Formula}

Surviving cells $(\%)=$ Mean OD of test compound / Mean OD of Negative control $\times 100$ Inhibiting cells $(\%)=100$ - Surviving cells

\section{RESULTS}

\section{Solubility Studies}

Amongst the 3 oils, it was found that CUR was more soluble in Kollisolv MCT $70(0.031226 \mathrm{mg} / \mathrm{mL})$ than Miglyol $812(0.0181 \mathrm{mg} / \mathrm{mL})$ and Phosal 53 (0.0066mg/ $\mathrm{mL})$, hence Kollisolv MCT 70 was selected as oil phase for the formulation.

\section{Screening of Surfactant and Cosurfactant}

For this study Tween 20, Tween 40 and Tween 80 were evaluated. Tween 80 was selected as surfactant, as it could solubilize more amount of oil $(20 \mu \mathrm{L})$ as compared to Tween $20(5 \mu \mathrm{L})$ and Tween $40(15 \mu \mathrm{L})$. The 
two cosurfactant screened were TPGS and PG. Pseudo ternary phase diagrams were plotted for Tween 80: TPGS (1:2), Tween 80: TPGS (1:3), Tween 80: PG (1:1) and Tween 80: PG (2:1) respectively (Figure 1). Based on these plots Tween 80: TPGS was selected in the ratio 1:2 as Smix since its phase diagram indicated the biggest region of NE formation.

\section{Thermodynamic Stability Studies}

Based on pseudo-ternary phase diagrams, 3 formulations were selected for study based on varying concentrations of oil and Smix. Visual observations were made after the NEs were subjected to the three evaluation conditions and NEs were checked for turbidity and phase separation. Based on the above observation final composition for the NE were selected containing Tween 80: TPGS 1:2.

\section{Optimization of NE}

Formulation was optimized by $3^{2}$ full factorial where concentration of Smix (x2) and oil (x1) were varied at 3 levels and the effect was observed on zeta potential (y1), particle size (y2) and PDI (y3) (Figure 2).

Zeta Potential (y1): The regression equation for zeta potential was found to be:

$\mathrm{y} 1=-13.79-1.18 * x 1+3.07 * x 2+2.00 * x 1 \times 2$

From this we can conclude that in this model, as the concentration of Smix increases zeta potential increases $(p<0.05)$ while as the oil concentration increases zeta potential decreases.

Particle Size (y2): The regression equation for particle size was found to be:

$\mathrm{y} 2=60.21+12.57 * \mathrm{x} 1-14.55 * \mathrm{x} 2+12.23 * \mathrm{x} 1 \mathrm{x} 2$

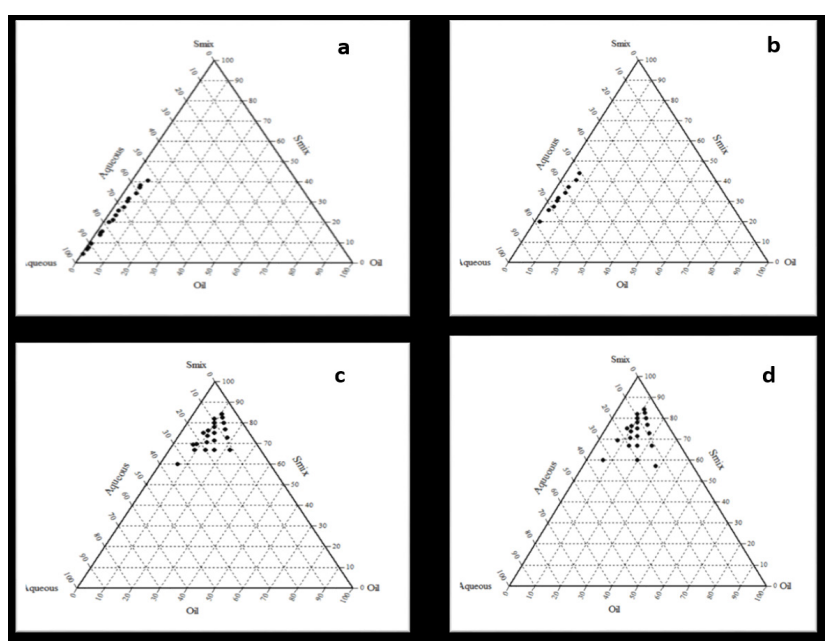

Figure 1: Pseudo ternary phase diagram for (a) Tween 80: TPGS (1:2), (b) Tween 80: TPGS (1:3), (c) Tween 80:PG(1:1), (d) Tween 80: PG(2:1)
From this we can conclude that in this model, as the concentration of oil increases particle size also increases while as the concentration of Smix increases particle size decreases $(p>0.100)$.

Polydispersity Index (y3): The regression equation for polydispersity index was found to be:

$\mathrm{y} 3=0.4826+0.0383 * \mathrm{x} 1-0.0125 * \mathrm{x} 2+0.0887 * \mathrm{x} 1 \mathrm{x} 2$

From this we can conclude that in this model, as the concentration of oil increases PDI also increases while as the concentration of Smix increases polydispersity index decreases $(p>0.100)$.

\section{Globule Size and Zeta Potential}

Globule Size of the NE was found to be $17 \mathrm{~nm}$ while zeta potential and PDI were $-12.8 \mathrm{mV}$ and 0.161 respectively.

\section{Physicochemical characterization of NE}

$\mathrm{pH}$, viscosity and transmittance of the $\mathrm{NE}$ were found to be $6.8,30 \mathrm{cP}$ and $93 \%$ respectively.

\section{Transmission Electron Microscopy}

In TEM images oil particles with smooth surface and spherical shape were observed. No crystal structure of the drug particles was observed. ${ }^{12}$ Figure 3(a), shows TEM image for the NE.

\section{Drug Content}

Drug content was found to be $97.99 \%$.

\section{Stability Studies}

Table 1 details out the results of room temperature and cold storage stability of the NE. Particle size, PDI and zeta potential were evaluated to establish stability. Visual

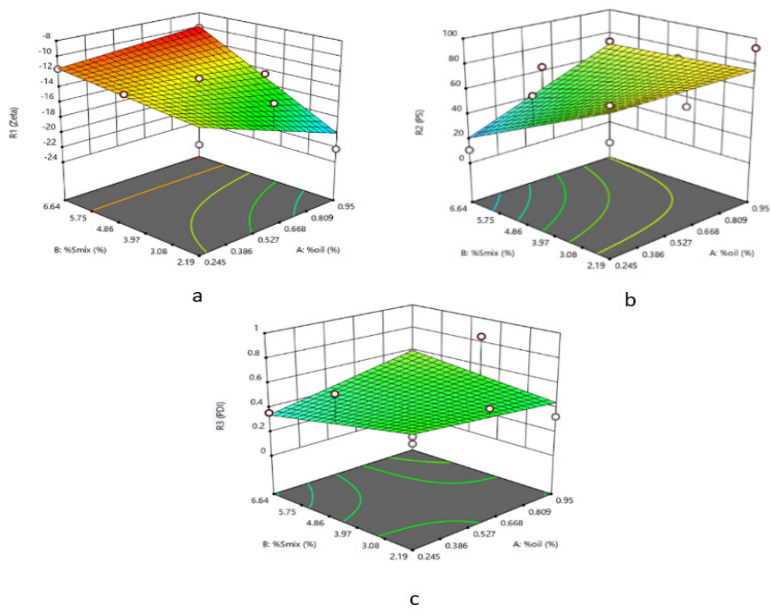

Figure 2: Response Surface Plot for effect of \% Oil and \% Smix on (a) Zeta Potential, (b) Particle Size and (c) Polydispersity Index. 
observation for phase separation was also noted. No aggregation or phase separation was noted.

\section{In-vitro Release Studies}

The $\mathrm{pH}$ of most biological fluids is in the range of 6.8 to 7.4 and hence a buffer of $\mathrm{pH} 7.2$ was used so as to mimic physiological conditions. In-vitro release studies revealed that formulation follows zero order kinetics with $79 \%$ of drug release up to $8 \mathrm{hrs}$. The NE showed constant amount of drug release throughout the study while pure drug showed almost $50 \%$ of release within 2 hr. Figure 3(b), shows graph for in-vitro release studies with sustained release of drug.

\section{In-vitro Evaluation in Cancer Cell Lines}

In-vitro evaluation in cancer cell lines revealed that cell growth was inhibited by the NE significantly more than the pure drug in both MIA Paca- 2 cell and Colo-205 cell lines. Also, efficacy was more in pituitary cancer cell line than colon cancer cell line (Figure 4).

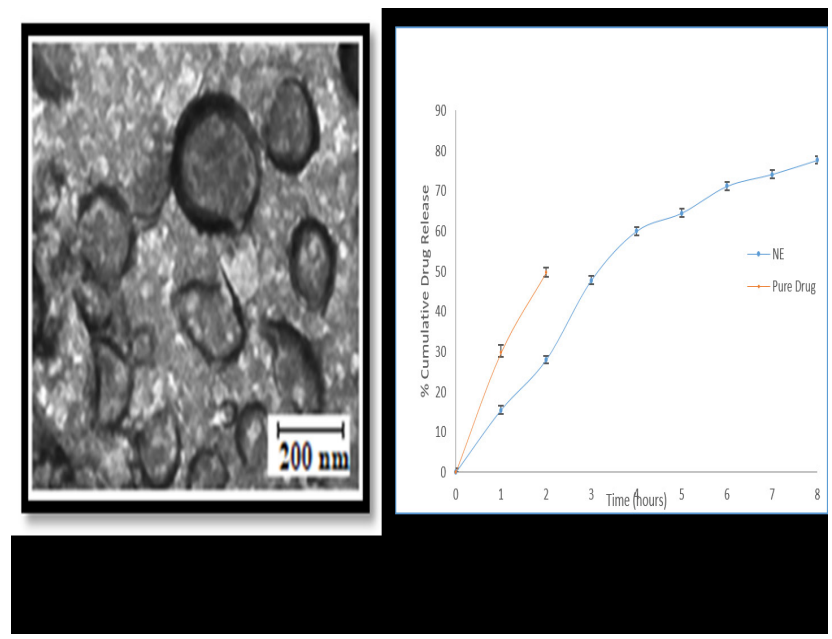

Figure 3: (a) TEM image for the NE, (b) In-vitro kinetics of CUR pure drug and CUR NE.

\section{DISCUSSION}

Pharmaceutical quality by design (QbD) is a systematic approach to product development and begins with predefined objectives. The approach involves product and process understanding a well as control. Quality risk management is also a major aspect addressed in the QbD approach. In this approach first the Quality Target Product Profile (QTPP) needs to be identified. This means that the product development is undertaken by keeping in mind the requirements and quality of the final product. In the current study, the main attributed required was the stability of the $\mathrm{NE}$, hence the optimization was performed by considering zeta potential, PDI and particle size since these are the primary indicators of stability of a NE. This is part of Design of Experiment (DoE). DoE is an excellent tool wherein we systematically manipulate factors according to a pre specified design. ${ }^{16-22}$ DoE also reveals relationships between input factors and output responses. In the current study, the concentration of Smix and concentration

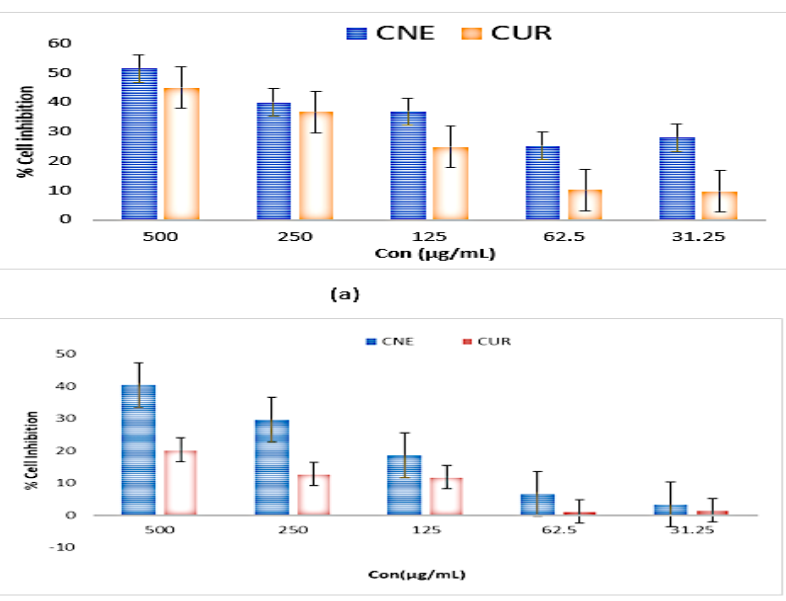

(b)

Figure 4: (a) Activity of formulation (NE) and pure drug (CUR) in Pituitary cancer cell-line (MIA PaCa-2) and (b) Colon cancer cell-line (Colo-205).

\begin{tabular}{|c|c|c|c|c|c|c|c|}
\hline \multirow{3}{*}{$\begin{array}{c}\text { Parameters } \\
\text { Stability } \\
\text { Conditions }\end{array}$} & \multicolumn{7}{|c|}{ Time (months) } \\
\hline & \multirow{2}{*}{0} & \multicolumn{2}{|c|}{1} & \multicolumn{2}{|c|}{2} & \multicolumn{2}{|c|}{3} \\
\hline & & RT & $\begin{array}{c}\text { Cold } \\
\text { Condition }\end{array}$ & RT & $\begin{array}{c}\text { Cold } \\
\text { Condition }\end{array}$ & RT & $\begin{array}{c}\text { Cold } \\
\text { Condition }\end{array}$ \\
\hline Particle Size(nm) & 17 & 39 & 25 & 45 & 30 & 47 & 39 \\
\hline PDI & 0.15 & 0.34 & 0.26 & 0.39 & 0.30 & 0.462 & 0.496 \\
\hline Zeta Potential & -12.6 & -12.9 & -12.6 & -13.5 & -14 & -13 & -12 \\
\hline $\begin{array}{c}\text { Visual } \\
\text { Observation }\end{array}$ & Clear & Clear & Clear & Clear & Clear & Clear & Clear \\
\hline
\end{tabular}

RT: Room Temperature $25^{\circ} \mathrm{C}$, Cold Condition: $2-8^{\circ} \mathrm{C}$ 
of oil were the input parameters (independent variables) while the zeta potential, particle size and PDI were output parameters (dependent variables).

In this case, we had to study the effect of two factors on the stability of the NE. Each factor needed to be assessed at various levels and interaction between these two factors was to be studied too. Hence, a $3^{2}$ full factorial design was selected for study; wherein each of the two independent factors were studied at three levels along with their interaction with each other.

$\mathrm{NE}$ is a thermodynamically unstable mixture of two essentially immiscible liquids with particle size ranging from $10 \mathrm{~nm}-100 \mathrm{~nm}$. As CUR is a highly water insoluble drug (hydrophobic), it is appropriate to formulate it as $\mathrm{o} / \mathrm{w} \mathrm{NE}$ as it will get solubilized in oil phase and will remain in solubilized form for longer time giving sustained release. NE formulation consists of oil phase, surfactant-cosurfactant and aqueous phase. In this study, our aim was to prepare stable o/w NE where aqueous phase is the external phase while oil phase is the internal phase. Formulation of NE starts with the selection of oil phase which in turn depends on the saturation solubility of the drug. Kollisolv MCT 70, which is a medium chain triglyceride, was selected as oil phase. To prepare a stable o/w NE, three surfactants having high HLB (Hydrophilic-Lipophilic balance) value were tried; Tween 20 (HLB 16.7), Tween 40(HLB 15.6) and Tween 80(HLB 15). Surfactants with high HLB values are highly water soluble and hence hydrophilic and stabilize o/w NE. The surfactant which could solubilize most amount of oil was selected. This was Tween 80 .

The combination of surfactant and cosurfactant gives the oil droplets the required stability through formation of an interfacial film as the oleophilic portion of surfactant-cosurfactant orients itself towards oil phase and hydrophilic portion towards the aqueous phase. ${ }^{23}$ Pseudo ternary phase diagram for each cosurfactant was plotted by aqueous titration method to delineate the region of NE formation. The NE formation region is slightly larger for PG than TPGS. Selected formulations for TPGS and PG were further subjected to the thermodynamic stability studies to avoid the selection of a metastable formulation. After these studies it was found to be that the formulations containing TPGS were highly stable. The formulation with Tween 80: TPGS $-1: 2$ ratios was selected based on stability.

$\mathrm{NE}$ can be formulated by number of techniques namely phase inversion, high pressure homogenization, microfluidization, ultrasonication, solvent evaporation and spontaneous emulsification. For CUR NE we have used high pressure homogenization technique in which emulsion is passed through orifice at $3000 \mathrm{rpm}$ for $15 \mathrm{~min} .{ }^{24}$
As per US FDA guidelines, nanoformulations are defined as those having particle size in the range of $10-100 \mathrm{~nm}$. The formulated NE had a particle size of $17 \mathrm{~nm}$. PDI is usually between $0-1$ where 0 (zero) represents a monodispersed system and 1 represents a poly dispersed. The observed PDI for the optimized NE was found to be 0.161 indicating uniform sized particles throughout the system. Zeta potential is a measure of the surface charge and hence is an indicator of the stability of emulsion. Zeta potential is governed by the physicochemical properties of the drug, polymer and vehicle. The developed formulation with a zeta potential of about $-12.8 \mathrm{mV}$ has shown good stability over the period of study. The $\mathrm{pH}$ of the NE found to be around 6.8 which is near physiological $\mathrm{pH}$ hence is expected to be non-irritant when given through oral or intravenous route. Viscosity is an important parameter for physicochemical characterization of NE; o/w emulsion usually have low viscosity as compared to w/o emulsions..$^{25}$ Transmittance is an indicator of the homogeneity of the system, hence higher the transmittance higher is uniformity of the NE. ${ }^{19}$

Transmission electron microscopy (TEM) is used to study the morphology and size of the particles of the dispersed phase. The developed NE showed spherical shape oil particles with smooth surfaces.

The prepared NE was stable at room temperature as well as cold conditions for a period of three months. There was no particle aggregation observed during storage.

To analyze the mechanism of drug release, the cumulative drug release was plotted in various kinetic models, such as zero order, first order, Higuchi and KorsmeyerPeppas; wherein the rate of drug release is a function of time, concentration, square root of time and diffusion coefficient respectively. ${ }^{26}$ The drug release from the NE was slow over a period of $8 \mathrm{hr}$, independent of initial concentration and hence the best fit model was found to be zero order. The pure drug however showed burst release of up to $50 \%$ in $2 \mathrm{hr}$ itself.

In-vitro evaluation in cancer cell line was performed by MTT assay method. It is a colorimetric assay for assessing cell metabolic activity giving cell viability and hence cell inhibition. The NE exhibited improved activity in both colon as well as pituitary cancer cell lines as compared to pure drug. The formulation found to be more effective on pituitary cancer cell line than colon cancer cell line.

Researchers have undertaken the development and optimization of CUR NE for improvement of anti-cancer activity, bioavailability as well solubility and stability. However, no systematic QbD based approach has yet been reported in this regard. 


\section{CONCLUSION}

A NE loaded with CUR and having excipients including Kollisolv MCT 70, Tween 80 and TPGS was optimized using a $3^{2}$ full factorial design. The optimized NE was stable and showed improved in vitro anti-cancer activity as compared to pure drug. QbD based approach in formulation development can lead to robust. Thermodynamically stable and more effective NEs.

\section{ACKNOWLEDGEMENT}

Nil.

\section{CONFLICT OF INTEREST}

The authors declare no conflict of interest.

\section{ABBREVIATIONS}

QbD: Quality by Design; CUR: Curcumin; NE: Nanoemulsion; TPGS: Tocopheryl polyethylene glycol 1000 succinate; PG: Propylene glycol; E: Emulsion; EG: Emulgel; DoE: Design of Experiment; Smix: Surfactant mixture; PDI: Polydispersity Index; TEM: Transmission Electron Microscopy; MTT: 3-(4,5-dimethylthiazol-2-yl)-2,5-diphenyltetrazolium bromide.

\section{REFERENCES}

1. Her C, Venier-Julienne MC, Roger E. Improvement of Curcumin Bioavailability for Medical Applications. Med Aromat Plants. 2019;07(06).

2. Kumar S. Role of nanoemulsion in pharmaceutical sciences: A review. Asian J Res Pharm Sci Biotechnol. 2014;2(1):1-15.

3. Shafiq S, Shakeel F, Talegaonkar S, Ahmad FJ, Khar RK, Ali M. Development and bioavailability assessment of ramipril nanoemulsion formulation. Eur $\mathrm{J}$ Pharm Biopharm. 2007;66(2):227-43.

4. Gupta A, Eral HB, Hatton TA, Doyle PS. Nanoemulsions: Formation, properties and applications. Soft Matter. 2016;12(11):2826-41. 5.

5. Mishra RK, Soni GC, Mishra RP. A Review Article: On Nanoemulsion. World J Pharm Pharm Sci . 2014;3(9):258-74. 6.

6. Azami SJ, Teimouri A, Keshavarz H, Amani A, Esmaeili F, Hasanpour H, et al. Curcumin nanoemulsion as a novel chemical for the treatment of acute and chronic toxoplasmosis in mice. Int J Nanomedicine. 2018;13:7363-74.

7. Guerrero $S$, Inostroza-Riquelme $M$, Contreras-Orellana $P$, Diaz-Garcia V, Lara P, Vivanco-Palma A, et al. Curcumin-loaded nanoemulsion: A new safe and effective formulation to prevent tumor reincidence and metastasis. Nanoscale. 2018;10(47):22612-22.
8. Reuter S, Eifes S, Dicato M, Aggarwal BB, Diederich M. Modulation of anti-apoptotic and survival pathways by curcumin as a strategy to induce apoptosis in cancer cells. Biochem Pharmacol. 2008;76(11):1340-51.

9. Baghbani F, Chegeni M, Moztarzadeh F, Hadian-Ghazvini S, Raz M. Novel ultrasound-responsive chitosan/perfluorohexane nanodroplets for imageguided smart delivery of an anticancer agent: Curcumin. Mater Sci Eng C. 2017;74:186-93.

10. Anuchapreeda S, Fukumori Y, Okonogi S, Ichikawa H. Preparation of Lipid Nanoemulsions Incorporating Curcumin for Cancer Therapy. Journal of Nanotechnology. 2012;2012.

11. Sood S, Jain K, Gowthamarajan K. Optimization of curcumin nanoemulsion for intranasal delivery using design of experiment and its toxicity assessment. Colloids Surfaces B Biointerfaces. 2014;113:330-7.

12. Tsai YM, Jan WC, Chien CF, Lee WC, Lin LC, Tsai TH. Optimised nanoformulation on the bioavailability of hydrophobic polyphenol, curcumin, in freely-moving rats. Food Chem. 2011;127(3):918-25. 13.

13. Desai NPM. Introduction to Quality by Design for Pharmaceuticals. $1^{\text {st }}$ ed. Pharma Med Press. 2017;1-22.

14. Kumar VP, Gupta NV. A Review on quality by design approach (QBD) for Pharmaceuticals Page. Int J Drug Dev Res. 2009;7(1):624-44.

15. Yozgatli V, Okur EM, Ayle S, Okur ON. Preparation and evaluation of QbD based fusidic acid loaded in situ gel formulations for burn wound treatment. Journal of Drug Delivery Science and Technology. 2019;52:110-21.

16. Desai N, Purohit R. Development of Novel High Density Gastroretentive Multiparticulate Pulsatile Tablet of Clopidogrel Bisulfate Using Quality by Design Approach. AAPS Pharm Sci Tech. 2017;18(8):3208-18.

17. Kumar M, Pathak K, Misra A. Formulation and characterization of nanoemulsion-based drug delivery system of risperidone. Drug Dev Ind Pharm. 2009;35(4):387-95.

18. Shafiq-un-Nabi S, Shakeel F, Talegaonkar S, Ali J, Baboota S, Ahuja A, et al. Formulation development and optimization using nanoemulsion technique: $A$ technical note. AAPS Pharm Sci Tech. 2007;8(2):E12-7.

19. Ahmed S, Gull A, Alam M, Aqil M, Sultana Y. Ultrasonically tailored, chemically engineered and "QbD" enabled fabrication of agomelatine nanoemulsion; optimization, characterization, ex-vivo permeation and stability study. Ultrason Sonochem. 2018;41:213-26.

20. Aqil M, Kamran M, Ahad A, Imam SS. Development of clove oil based nanoemulsion of olmesartan for transdermal delivery: Box-Behnken design optimization and pharmacokinetic evaluation. J Mol Liq. 2016;214:238-48. 21.

21. Ahmad N, Ahmad R, Alam MA, Samim M, Iqbal Z, Ahmad FJ. Quantification and evaluation of thymoquinone loaded mucoadhesive nanoemulsion for treatment of cerebral ischemia. Int J Biol Macromol. 2016;88:320-32.

22. $\mathrm{Xu} X$, Khan $M$, Burgess D. A Quality by Design $(\mathrm{QbD})$ case study on liposomes containing hydrophilic API:II. Screening of critical variables and establishment of design space at laboratory scale. Int $\mathrm{J}$ of Pharmaceutics. 2012;423(2):543-53.

23. Yu LX, Amidon G, Khan MA, Hoag SW, Polli J, Raju KG, et al. Understanding Pharmaceutical Quality by Design. AAPS Journal. 2014;16(4):77183.24.

24. Boche M, Pokharkar V. Quetiapine Nanoemulsion for Intranasal Drug Delivery: Evaluation of Brain-Targeting Efficiency. AAPS Pharm Sci Tech. 2017;18(3):686-96. 25

25. Gurpret, Singh . Review of Nanoemulsion Formulation and Characterization Techniques. Indian J Pharm Sci. 2018;80(5):781-9.

26. Barzegar-Jalali M, Khosro A, et al. Kinetic Analysis of Drug Release From Nanoparticles. J Pharm Pharmaceut Sci. 2008;11(1):167-77. (www. cspsCanada.org) 
PICTORIAL ABSTRACT

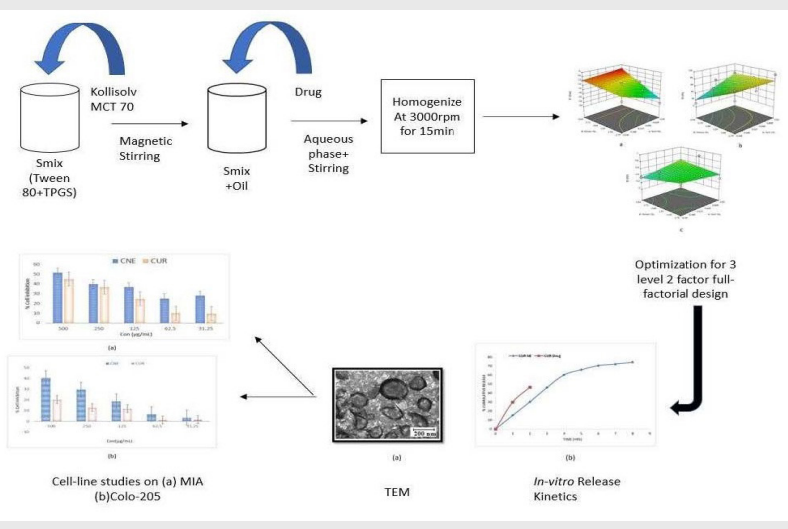

\section{SUMMARY}

A QbD based approach for the development and optimization of CUR NE was undertaken. The optimized NE was found to be stable and released the drug in a sustained manner. It showed better in vitro anti-cancer activity than the pure drug. Thus, a QbD based approach in formulation development can lead to robust, therapeutically more effective and thermodynamically stable NEs.

\section{About Authors}

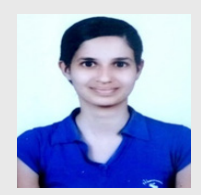

Ms. Shambhavi Acharya has completed her M. Pharm in Quality Assurance Techniques from Poona College of Pharmacy. She is currently working with Wockhardt Ltd., Aurangabad, Maharashtra.

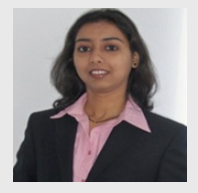

Ms. Preeti Tamane has completed her M. S. (Pharm.) in Natural Products. She has a decade of industrial experience in the areas of analytical method development and regulatory affairs. She is currently Assistant Professor. Department of Drug Regulatory Affairs, Poona College of Pharmacy.

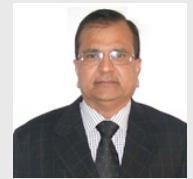

Mr. Shyam Khante has completed his M.Pharm in Pharmaceutics and also DBM and has over 40 years of experience at various positions in Indian and multinational pharmaceutical companies. He is currently Professor Emeritus. Department of Quality Assurance, Poona College of Pharmacy.

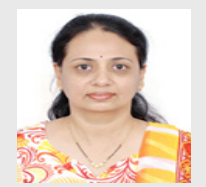

Professor Dr. Varsha Pokharkar has completed her M.Pharm in Pharmaceutical Technology from UICT, Mumbai and Ph.D. from National Chemical Laboratory, Pune. She has more than 25 years of experience an academician and researcher. Her areas of interest include development of novel and targeted drug delivery systems. She is currently the Head, Department of Pharmaceutics and Vice Principal, Poona College of Pharmacy.

Cite this article: Acharya SD, Tamane PK, Khante SN, Pokharkar VB. QbD Based Optimization of Curcumin Nanoemulsion: DoE and Cytotoxicity Studies. Indian J of Pharmaceutical Education and Research. 2020;54(2):32936. 